\title{
Damping properties of nickel-added modified zinc alloys
}

\section{Umashankar* and K. Annamalai}

School of Mechanical and Building Sciences, VIT, Chennai campus, Chennai-600127, India.

Email: mumashankar_m@yahoo.com; kannamalai@vit.ac.in $\mathrm{Ph}:+919901933334$.

\begin{abstract}
The objective of the present work is to investigate the effect of $\mathrm{Ni}$ content on the damping behaviour of zinc modified alloy using a dynamic mechanical analyser. The modified zinc alloys were prepared for different additions of $\mathrm{Ni}$ content using the liquid metallurgical technique. Damping properties such as storage modulus, loss modulus and specific damping capacity were studied for both zinc alloy and modified zinc alloy over a temperature range of $30{ }^{\circ} \mathrm{C}$ to $300{ }^{\circ} \mathrm{C}$. The results showed that the specific damping capacity and loss modulus of both zinc and modified zinc alloys increased with increases in temperature, but storage modulus decreased with temperature. The addition of Ni into zinc alloys improves its specific damping capacity due to the thermal expansion mismatch which induced a dislocation density between the matrix and alloy. The specific damping capacity was found to be high at higher temperature $\left(300^{\circ} \mathrm{C}\right)$ due to the intrinsic damping of zinc alloy and thermo-elastic damping between the zinc alloy and Ni particulate. In the present work, it was also found that the contribution of thermoelastic damping is significant throughout the temperature range considered.
\end{abstract}

Keywords: DMA; ZA27 alloys; specific damping; storage modulus.

\section{INTRODUCTION}

Zinc alloys have received much research interest over the decades and are widely used as journal bearing materials because of their excellent specific strength and corrosion resistance. Zinc alloy is a very high performance alloy in terms of strength and hardness [1]. It is stronger and has a better wear resistance compared to copper, tin-lead, and aluminum-based alloys which were studied on and reported by Bekir and Sadik Unlu [2]. Zinc alloys have the ability to damp out vibrations and noise, but they fail to perform at high temperatures. Damping is one of the significant properties important for the suppression of vibration in aerospace, submarine and automotive structures. This is because if structural materials have an intrinsic damping capacity, there will be no need for active dampers such as electromechanical or hydro-mechanical dampers. When designing components, higher damping material would be selected to reduce the cost of the component and attenuate the vibration. Montalba et.al demonstrated that the addition of functional particles such as PBN, PLZT and SiC with an Al master alloy matrix improves damping capacity [3]. Hamdullah and Hasan Bas investigated the tribological properties of silicon containing zinc-aluminum based journal bearings using a purposebuilt journal bearing test rig [4]. The modification of alloy by introducing high strength materials leads to a modification of the alloy's damping properties the by combination of 
both lower density and higher strength metallic phases. The addition of a secondary phase alloy as graphite particles improves both the ductility and toughness of the modified alloy along with higher specific strength and modulus which leads to improved damping capacity as shown in a study by Girish et al. [5]. Mitrovic et al. reviewed contemporary research in the area of hybrid composites based on zinc and aluminium alloys reinforced with $\mathrm{SiC}$ and had showed that graphite particles have good tribological properties compared to pure alloys [6]. From the study of the literature, it was found that only a small number of works have been reported on ZA alloys with different reinforcements. No work has been reported on ZA-based alloys with Nickel (Ni) as reinforcement. Hence, the present research work is focused on the investigation of the addition of $\mathrm{Ni}$ as reinforcement to ZA alloy processed using the liquid metallurgy technique. The damping behaviour of the modified ZA alloy was measured using a Dynamic Mechanical Analyser over a range of temperatures between $30^{\circ} \mathrm{C}$ to $300^{\circ} \mathrm{C}$. The criterion for the selection of this range of temperature was based on the work reported in the literature[1]. The Loss modulus, storage modulus and specific damping capacity of the modified ZA alloy were computed.

\section{METHODS AND MATERIALS}

\section{Experimental Details}

The selection of a proper matrix material and a suitable reinforcement is a challenging task based on the extensive literature survey conducted. In the present work, Zinc, Aluminium, magnesium, and copper metal were chosen as the alloying elements and $\mathrm{Ni}$ in its rock form was selected as the reinforcement. The $\mathrm{Ni}$ used as reinforcement in the present investigation was purchased from a mineralogical research company. The weight percentage of the $\mathrm{Ni}$ added was $2.5,5,7.5$ and $10 \%$ to prepare the modified alloy. The known quantities of zinc alloy was cleaned using $10 \%$ sodium hydroxide $(\mathrm{NaOH})$ solution to remove acid and basic impurities, and then dried. The cleaned and dried zinc alloy was melted up until it was superheated using a furnace in inert atmosphere (nitrogen gas).

Table 1. Chemical composition of ZA-27 alloy (ASTM B669-82).

\begin{tabular}{cccc}
\hline Aluminium & $\mathrm{Cu}$ & $\mathrm{Mg}$ & $\mathrm{Zn}$ \\
\hline $25-28 \%$ & $1-2 \%$ & $0.01-0.02 \%$ & Balance \\
\hline
\end{tabular}

A mix of zinc, aluminium, magnesium and copper molten metals as per the composition given in the Table 1 was combined in a common crucible using a stainless steel impeller. After the mixing, the crucible was placed in the furnace at a temperature range of $450-500^{\circ} \mathrm{C}$. The Ni particles were preheated in a muffle furnace. Specimens with the required dimensions were machined from the prepared castings, and usually the middle portion of the castings is selected for this purpose. All specimens were polished for a smooth surface finish using different grits of silicon carbide papers. The dynamic mechanical analyser (DMA) is a commercial instrument based on forced vibration as shown in Figure 1. It consists primarily of an electromagnetic driver, a linear variable differential transformer (LVDT), a flexure pivot, sample arms and a clamp. A thermocouple is attached close to the sample to record its temperature. The damping specimen size $\left(70 \times 10 \times 2 \mathrm{~mm}^{3}\right)$ was fixed firmly at both ends. A microprocessor control unit automatically maintains the strain amplitude, frequency and temperature program 
conditions. The damping specimens were subjected to a flexural type strain of 250/300 $\mu \mathrm{m}$ peak to peak using an electromagnetic driver. The resultant stress on the specimen was computed using a precise LVDT. With the state of the art microprocessor systems, all of the complex calculations were easily performed and the plots of storage modulus $\left(E^{1}\right)$ and loss modulus $\left(E^{11}\right)$ were obtained [5]. Strain amplitudes were selected from $10^{-4}$ to $10^{-5}$ and the $30^{\circ} \mathrm{C}$ to $300^{\circ} \mathrm{C}$ temperature range was selected for both the heating and cooling cycles. The experiment was performed for $0,2.5,5,7.5$ and $10 \%$ weight of $\mathrm{Ni}$ reinforced ZA alloy samples. For each composition, three specimens were tested as microstructural in-homogeneity was supposed to cause considerable variations in behaviour [7]. The experimental values of specimens are as indicated below in Table 2 .

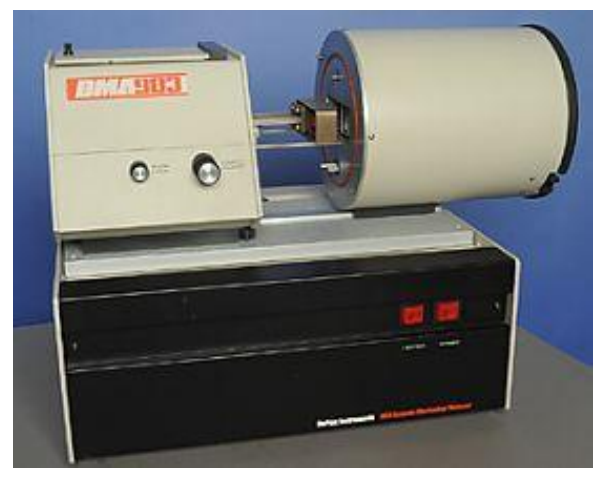

Figure 1. Dynamic Mechanical Analyser Equipment

Table 2. a) Storage Modulus $\left(E^{1}\right)$ b) Loss Modulus $\left(E^{11}\right)$ and c) Damping Capacity (Tan ø) data of ZA/Ni modified alloy as a function of Temperature

\begin{tabular}{|c|c|c|c|c|c|}
\hline \multirow{3}{*}{$\begin{array}{c}\text { Temperature } \\
{ }^{\circ} \mathrm{C}\end{array}$} & \multicolumn{5}{|c|}{ Weight percentage of Ni content } \\
\hline & $0 \%$ Ascast & $2.5 \%$ & $5 \%$ & $7.5 \%$ & $10 \%$ \\
\hline & $\mathrm{E}^{1}(\mathrm{GPa})$ & $\mathrm{E}^{1}(\mathrm{GPa})$ & $\mathrm{E}^{1}(\mathrm{GPa})$ & $\mathrm{E}^{1}(\mathrm{GPa})$ & $\mathrm{E}^{1}(\mathrm{GPa})$ \\
\hline & \multicolumn{5}{|c|}{ a) Storage Modulus } \\
\hline 50 & 127.13 & 151.10 & 152.80 & 153.30 & 153.89 \\
\hline 100 & 125.70 & 149.28 & 150.42 & 151.93 & 152.30 \\
\hline 150 & 121.41 & 145.71 & 146.42 & 147.74 & 147.69 \\
\hline 200 & 109.99 & 132.85 & 137.85 & 140.64 & 136.92 \\
\hline 250 & 89.99 & 109.28 & 115.70 & 121.29 & 114.61 \\
\hline \multirow[t]{3}{*}{300} & 64.28 & 81.43 & 88.76 & 95.71 & 87.71 \\
\hline & \multicolumn{5}{|c|}{ b) Loss Modulus } \\
\hline & $\mathrm{E}^{11}(\mathrm{GPa})$ & $\mathrm{E}^{11}(\mathrm{GPa})$ & $\mathrm{E}^{11}(\mathrm{GPa})$ & $\mathrm{E}^{11}(\mathrm{GPa})$ & $\mathrm{E}^{11}(\mathrm{GPa})$ \\
\hline 50 & 2.20 & 2.05 & 2.18 & 2.56 & 2.56 \\
\hline 100 & 2.44 & 2.43 & 2.56 & 2.82 & 3.07 \\
\hline 150 & 3.16 & 3.84 & 4.10 & 3.84 & 4.48 \\
\hline 200 & 4.92 & 7.05 & 7.88 & 7.37 & 8.46 \\
\hline 250 & 8.28 & 11.79 & 13.65 & 13.46 & 13.97 \\
\hline \multirow[t]{2}{*}{300} & 10.76 & 14.48 & 17.30 & 18.39 & 17.56 \\
\hline & \multicolumn{5}{|c|}{ c) Damping Capacity (Tan $\emptyset$ ) } \\
\hline 50 & 0.017 & 0.013 & 0.014 & 0.016 & 0.016 \\
\hline 100 & 0.019 & 0.016 & 0.017 & 0.018 & 0.020 \\
\hline 150 & 0.026 & 0.026 & 0.028 & 0.026 & 0.030 \\
\hline 200 & 0.044 & 0.069 & 0.057 & 0.052 & 0.069 \\
\hline 250 & 0.120 & 0.107 & 0.118 & 0.119 & 0.122 \\
\hline 300 & 0.167 & 0.177 & 0.194 & 0.192 & 0.200 \\
\hline
\end{tabular}




\section{RESULTS AND DISCUSSION}

\section{Effect of Temperature and Ni Content on Damping Behaviour}

Figure 2 shows the storage modulus, loss modulus, and damping capacity of ZA modified alloy as a function of the addition of $\mathrm{Ni}$ and working temperature. The trend shows that the loss modulus significantly increased with increases in temperature, but the storage modulus had decreased. On the other hand, both specific damping capacity and loss modulus increased with increases in Ni content as per the theory proposed by Zener based on the elastothermodynamic damping mechanism[8]. It is also based on the fact that energy is dissipated by the irreversible heat flow within a material caused by stressinduced thermal gradients.
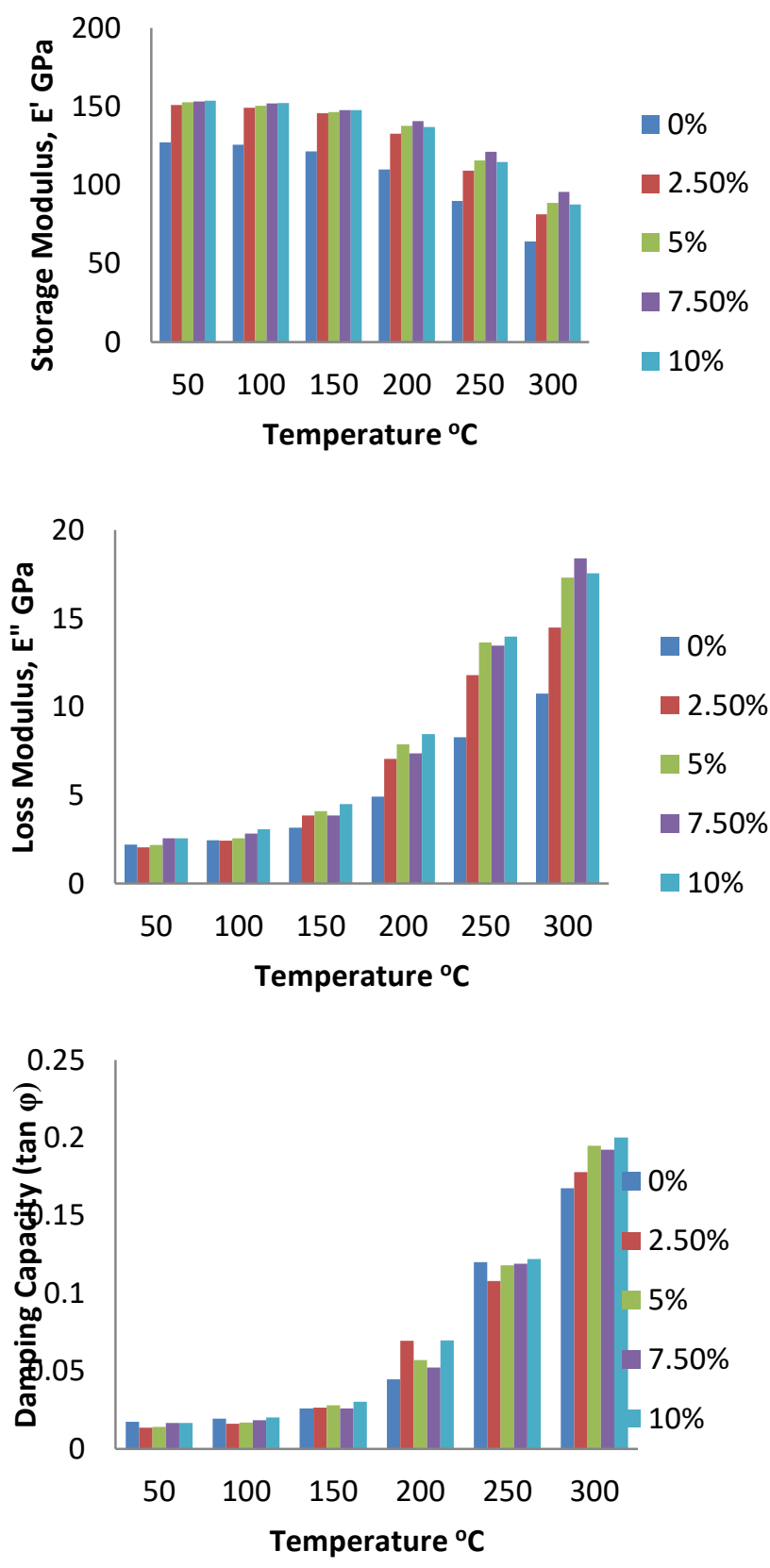

Figure 2. Effect of temperature and Ni content on the damping properties of the modified ZA-27 alloy. 
These variations were more prominent at temperatures above $150^{\circ} \mathrm{C}$, particularly between $150^{\circ}$ and $280^{\circ} \mathrm{C}$ due to the grain boundary relaxation in the modified alloy. This happened due to grain modification as mentioned in the literature [9]. The various damping mechanisms that may be actively operating in the modified alloy are thermoelastic damping, grain-boundary damping, thermal-mismatch dislocation damping, and interface damping. The first two mechanisms are mainly matrix-related, while the remaining two are due to the presence of the Ni particulates[10]. Thermo-elastic damping originates in the coupling that exists between stress and strain, and the conjugate pair temperature and entropy. Thermo-elastic coupling is the linear expansion of the length of a material which can be achieved either by stretching it or by heating it. In the thermoelastic damping mechanism, the vibration energy is dissipated to the surroundings through irreversible heat which leads to stress-induced thermal gradient in the damping specimens[11]. The thermo-elastic coupling effect may become evident when a material undergoes a heterogeneous deformation such as beam bending in the Dynamic Mechanical Analyser equipment as reported in the literature[12]. The uniaxial strain induced by bending varies linearly with the distance from the neutral axis for isotropic materials such as the particulate reinforced modified alloy used in the present study. Thus, an alternating temperature gradient is set up across the opposite face of the vibrating beam. Relaxation occurs through heat flow from the hotter, compressed layers to the colder, stretched layers. Analysis predicted the thermoelastic damping to be calculated as,

$$
Q_{T e}^{-1}=\frac{\Delta_{T E} \omega \tau}{1+(\omega \tau)^{2}}
$$

where $\Delta_{\mathrm{TE}}=$ Thermoelastic relaxation strength $=\mathrm{E}_{\mathrm{U}} \alpha^{2} \mathrm{~T}_{0} / \mathrm{c}_{\sigma} ; \mathrm{E}_{\mathrm{U}}=$ Young's modulus (Unrelaxed type); $\alpha=$ coefficient of thermal expansion; $\mathrm{T}_{0}=$ Absolute temperature, $\mathrm{c}_{\sigma}$ $=$ specific heat per unit volume; $\omega=$ angular frequency; $\tau=$ relaxation time $=c_{\sigma} h^{2} / \pi^{2}$ $\mathrm{K} ; \mathrm{h}$ = beam thickness; $\mathrm{K}=$ thermal conductivity.

In the modified alloy, differences in CTE of both zinc alloy and Ni particulate influence local deformation around the Ni particulate. Therefore, it may be anticipated that the thermal gradient induced thermo-elastic damping is higher in the ZA/Ni modified alloy than in unreinforced matrix alloy. This fact was also mentioned already in the literature [13]. Furthermore, according to equation (1), thermo-elastic damping is frequency dependent and reaches a maximum when $\omega \tau=1$ (unity) [14]. The peak frequency, called the Zener relaxation frequency is determined as

$$
\mathrm{f}=\omega / 2 \pi=1 / 2 \pi \tau
$$

In the present work, the damping measurements have been carried out at the natural frequency of the specimen in each case so that $\omega \tau=1$. The estimated contribution to damping due to the thermoelastic effect at specific temperatures is given in Table 3 . The calculations indicated that the thermoelastic contribution to damping was small but significant throughout the temperature range. Referring to Zener, damping due to the thermoelastic effect is negligible below $100 \mathrm{~Hz}[8]$. In the present investigation, the operating frequency was below $10 \mathrm{~Hz}$, so a lesser contribution was obtained as expected. 
Table 3. The estimated contribution to damping due to the thermoelastic effect on ZA modified alloy.

\begin{tabular}{ccccc}
\hline Temp, ${ }^{\circ} \mathrm{C}$ & \multicolumn{4}{c}{ Tan $\varphi$} \\
\cline { 2 - 5 } & \multicolumn{3}{c}{$0 \%$} & \multicolumn{3}{c}{$10 \%$} \\
\cline { 2 - 5 } & Calculated,10-3 & Experimental, $10^{-2}$ & Calculated, $10^{-3}$ & Experimental, $10^{-2}$ \\
\hline 30 & 1.42 & 1.48 & 1.69 & 1.57 \\
50 & 1.48 & 1.73 & 1.79 & 1.67 \\
100 & 1.85 & 1.94 & 2.25 & 2.02 \\
150 & 2.28 & 2.61 & 2.77 & 3.04 \\
200 & 2.7 & 4.47 & 3.55 & 6.97 \\
250 & 3.5 & 12 & 4.53 & 12.2 \\
\hline
\end{tabular}



Figure 3. Effect of Ni on microstructure of modified ZA-27 alloy (a) ZA-27 alloy, b) $2.5 \%$ of Ni/ZA alloy, c) $5 \%$ of Ni/ZA alloy, and d) $10 \%$ of Ni/ZA alloy.

\section{Grain Boundary Damping}

Zener [8] predicted that boundary relaxation should occur due to viscous sliding between adjacent grains in a material at appropriate temperatures. Boundary relaxation between the grain boundaries converts mechanical vibration (energy) into thermal energy under cyclic vibration. The thermal energy developed between the grains due to friction between them and heat energy was dissipated to the surroundings [14]. It has been observed in [15] that the grain size of matrix metal/alloy decreases with the addition of $\mathrm{Ni}$. Hence, the fine grained micro structure of ZA/Ni modified alloy shown in Figure 3 shows an important role in the dissipation of strain energy leading to grain boundary damping [7] as observed under the optical microscope. In the present work, the commercially obtained ZA matrix alloy contained several metastable phases so that there may be one or more defect parameters involved. This distribution of relaxation parameters resulted in a substantial broadening of grain boundary relaxation peak which appeared at a high temperature range of $280^{\circ} \mathrm{C}-300^{\circ} \mathrm{C}$. It was observed that the ZA matrix alloy exhibited a grain boundary peak at higher temperatures where other physical and 
mechanical properties suffered severe deterioration. However, the low temperature tail of such a peak can be exploited for its high damping capacity.

\section{Thermal Mismatch Induced Dislocation Damping}

This mechanism is based on the dislocation movement lagging behind the applied stress. The coefficient of thermal expansion (CTE) values for the ZA matrix and $\mathrm{Ni}$ were $26 \times 10^{-6} /{ }^{\circ} \mathrm{C} \& 7.4 \times 10^{-6} /{ }^{\circ} \mathrm{C}$ respectively. Due to the large difference in the CTE values, dislocations were generated in the alloy during cooling from the high fabrication temperatures and subsequent thermal loading[16]. These dislocations generated to accommodate the residual thermal stresses are located primarily near the interface, and their density decreases with the increase in distance from the interface[17]. Therefore, there is an increase in dislocation density in the modified alloy when compared to the base material which contributed to an increase in damping.

The mechanism by which the dislocations are generally considered to affect damping behaviour is given by the Granato-Lucke mechanism[18]. This mechanism assumes that losses occur due to dislocations breaking away from weak pinning points under cyclic loading. These breakaway dislocations which are still attached to the strong pinning points execute a sweeping motion under the application of an applied stress which is associated with a dissipation of energy in proportion to the area traced. According to the Granato-Lucke dislocation theory, the internal friction of a material is proportional to the dislocation density present, and is given by Equation (3),

$$
Q^{-1}=\frac{C_{1}}{\varepsilon_{0}} e^{\frac{-c_{2}}{\varepsilon_{0}}}
$$

where $\mathrm{C}_{1}$ and $\mathrm{C}_{2}$ are material constants and $\mathrm{C}_{1}$ is proportional to dislocation density in the matrix. $\varepsilon_{0}$ is the strain amplitude. The contribution of dislocations to damping may be expected to fall with increasing temperatures since its concentration has decreased as demonstrated by Arsenault and Shi [19]. Thus, dislocation damping may constitute a large percentage of the overall damping in the ZA / Ni modified alloy at room temperatures but decreased in its importance as the temperature was increased.

In the present work, dislocation density in the case of ZA/Ni modified alloy was calculated for the alloy at certain specific temperatures using the relation,

$$
\begin{aligned}
& \rho=\frac{B f \varepsilon}{b(1-f) t} \\
& \text { where strain } \varepsilon=\frac{\Delta_{C T E} X T}{2}
\end{aligned}
$$

where $\Delta_{\mathrm{CTE}}=$ Difference between the CTE values of the matrix and $\mathrm{Ni} ; \Delta \mathrm{T}=$ Temperature difference between operating and the stress free state; Stress free state temperature $=765$ $\mathrm{K}$ (Melting temperature); $\mathrm{B}=\mathrm{constant}=12$ for spherical particulate (aspect ratio $=1$ ); $\mathrm{f}=$ volume fraction $=0.1075 ; \mathrm{b}=$ Burger's vector $=0.28 \mathrm{~nm} ; \mathrm{t}=$ particulate dimension (diameter) $=50 \mu \mathrm{m}$.

The dislocation density for ZA / Ni at room temperature was found to be 4.9674 $\mathrm{x} 10^{11} / \mathrm{m}^{2}$. It was observed from the plot that the dislocation density decreased with increases in operating temperature so that the contribution to damping by dislocation generation and motion was significant only at lower temperatures. 


\section{Matrix /Ni Interface Damping}

One of the attractive characteristics of modified alloy is the possibility of introducing sources of damping by controlling the nature of the matrix/ $\mathrm{Ni}$ interface. A poorly bonded interface can contribute to damping through a sliding friction mechanism [20]. However, gains in damping capacity through interfacial sliding will be accompanied by losses in the stiffness and strength of the alloy. On the other hand, a well-bonded interface could also lead to increased damping via an increased dislocation density near the fiber-matrix interface $[21,22]$. Therefore, it is possible to develop a modified alloy with a combination of well-bonded and poorly-bonded regions to enhance damping while maintaining stiffness. In the case of particulate reinforced modified alloy, the interfacial effects on damping may become more significant due to the heterogeneity and stress concentration effects that are present as a result of the particulate in the metal matrix [23]. Keeping in view the Schoeck's equation, the following equation may be utilised to predict the contribution of interfaces to high temperature damping in Ni particulate reinforced ZA modified alloy,

$$
Q^{-1}=\frac{8(1-\gamma) \sum a_{3} i\left(\overline{\left.P_{13}\right) l^{2}}\right.}{P_{13}{ }^{2} \pi(2-\gamma) V}
$$

where $\mathrm{P}_{13}=$ external shear stress, $\mathrm{V}=$ volume of the sample, $\gamma=$ Poisson's ratio of the matrix, $\mathrm{a}_{\mathrm{i}}=$ radius of the oblate spheroid 'I' $\left(\overline{\mathrm{P}}_{13}\right)$, and $\mathrm{I}=$ component of $\mathrm{P}_{13}$ in the plane of the spheroid I which can be relaxed.

$$
Q^{-1}=\frac{4.5(1-\gamma) V P}{\pi^{2}(2-\gamma)}
$$

In the present work, $\gamma=$ poisson's ratio of the ZA matrix alloy $=0.33 ; \mathrm{V}_{\mathrm{P}}=$ volume fraction of Ni particulate $=0.1075(4 \mathrm{wt}$. \%) yields.

$$
\mathrm{Q}^{-1}=0.0196
$$

This is the contribution to damping due to interface effects in ZA/Ni modified alloy. The interface damping in the alloy under study becomes active in the higher temperature range. This is because at elevated temperatures, the ZA matrix becomes soft relative to the Ni particulate so that reversible movements began to occur at the interface, assuming a viscous boundary existed at the interface [1].

\section{CONCLUSIONS}

In the present work, damping properties of modified Zinc alloys were studied by considering $\mathrm{Ni}$ as reinforcement. The following conclusions were drawn:

a) The damping properties of $\mathrm{ZA}-27 / \mathrm{Ni}$ alloy was studied in the temperature range of $30^{\circ} \mathrm{C}$ to $300^{\circ} \mathrm{C}$.

b) In the present work, it was found that the addition of Ni to ZA-27 alloy provided higher damping capacity and greater loss modulus.

c) The temperature dependence study of damping showed an increase in the damping capacity with increases in temperature, accompanied by decreases in storage modulus.

d) This increase of damping capacity and loss modulus with decreases in storage modulus is found to be predominant between $150^{\circ} \mathrm{C}$ to $280^{\circ} \mathrm{C}$. 
e) In the present work, several damping mechanisms were evaluated using theory and equations wherever available. It was found that the dislocations produced by the CTE mismatch offer a large contribution at lower temperatures in addition to the intrinsic damping provided by the ZA-27 matrix alloy.

f) In the present work, it was also observed that the contribution of thermoelastic damping was significant throughout the temperature range considered.

\section{ACKNOWLEDGEMENTS}

The authors would like to be obliged to K. S. Institute of Technology, Bangalore for providing laboratory facilities to carry out the research work.

\section{REFERENCES}

[1] Sastry S, Krishna M, Uchil J. A study on damping behaviour of aluminite particulate reinforced ZA-27 alloy metal matrix composites. Journal of Alloys and Compounds. 2001;314:268-74.

[2] Ünlü BS. Investigation of tribological and mechanical properties of metal bearings. Bulletin of Materials Science. 2009;32:451.

[3] Montalba C, Eskin D, Miranda A, Rojas D, Ramam K. Effect of electroceramic particles on damping behaviour of aluminium hybrid composites produced by ultrasonic cavitation and mechanical stirring. Materials \& Design. 2015;84:1107.

[4] Çuvalcı H, Baş H. Investigation of the tribological properties of silicon containing zinc-aluminum based journal bearings. Tribology International. 2004;37:433-40.

[5] Girish B, Prakash K, Satish B, Jain P, Prabhakar P. An investigation into the effects of graphite particles on the damping behavior of ZA-27 alloy composite material. Materials \& Design. 2011;32:1050-6.

[6] Mitrović S, Babić M, Stojanović B, Miloradović N, Pantić M, Džunić D. Tribological potential of hybrid composites based on zinc and aluminium alloys reinforced with $\mathrm{SiC}$ and graphite particles. Tribology in Industry. 2012;34:17785.

[7] Mohanty S, Routara B. A review on machining of metal matrix composites using nanoparticle mixed dielectric in electro-discharge machining. International Journal of Automotive \& Mechanical Engineering. 2016;13: 3518-39.

[8] Zener C. Elasticity and anelasticity of metals: University of Chicago press; 1948.

[9] Deng KK, Li JC, Nie KB, Wang XJ, Fan JF. High temperature damping behavior of as-deformed $\mathrm{Mg}$ matrix influenced by micron and submicron SiCp. Materials Science and Engineering: A. 2015;624:62-70.

[10] Prasad DS, Shoba C, Prasad BS. Effect of white layer on the damping capacity of metal matrix composites. Materials Science and Engineering: A. 2014;591:78-81.

[11] Prasad DS, Shoba C. Effect of heat treatment on the white layer and its effect on the damping behavior of metal matrix composites. Materials Science and Engineering: A. 2014;599:25-7.

[12] Prasad DS, Shoba C. Experimental evaluation onto the damping behavior of $\mathrm{Al} / \mathrm{SiC} / \mathrm{RHA}$ hybrid composites. Journal of Materials Research and Technology. 2016;5:123-30. 
[13] Singh S, Pal K. Effect of surface modified silicon carbide particles with $\mathrm{Al}_{2} \mathrm{O}_{3}$ and nanocrystalline spinel $\mathrm{ZnAl}_{2} \mathrm{O}_{4}$ on mechanical and damping properties of the composite. Materials Science and Engineering: A. 2015;644:325-36.

[14] Gu M, Chen Z, Wang Z, Jin Y, Huang J, Zhang G. Damping characteristics of ZnAl matrix composites. Scripta Metallurgica et Materialia. 1994;30(10): 1321-6.

[15] Elomari S, Lloyd D. Proceedings of Processing properties and applications of cast metal matrix composites (Edited by P.K.Rohatgi). The Minerals, Metals and Materials Society. 1996;201.

[16] Khan M, Dixit G. Erosive wear response of SiCp reinforced aluminium based metal matrix composite: Effects of test environments. Journal of Mechanical Engineering and Sciences. 2017;14:2401-14.

[17] Kinra VK, Wolfenden A. M3D: mechanics and mechanisms of material damping. ASTM Philadelphia, PA; 1992.

[18] Ibrahim I, Mohamed F, Lavernia E. Particulate reinforced metal matrix composites - a review. Journal of Materials Science. 1991;26:1137-56.

[19] Arsenault R, Shi N. Dislocation generation due to differences between the coefficients of thermal expansion. Materials Science and Engineering. 1986;81:175-87.

[20] Sankar HR, Srikant R, Krishna PV, Rao VB, Babu PB. Estimation of the dynamic properties of epoxy glass fabric composites with natural rubber particle inclusions. International Journal of Automotive and Mechanical Engineering. 2013;7:968-80.

[21] Bobić B, Vencl A, Babić M, Mitrović S, Bobić I. The Influence of corrosion on the microstructure of thermally treated ZA27/SiCp composites. Tribology in Industry. 2014;36(1):33-9.

[22] Bachtiar D, Sapuan S, Hamdan M. Flexural properties of alkaline treated sugar palm fibre reinforced epoxy composites. International Journal of Automotive and Mechanical Engineering. 2010;1:79-90.

[23] Miloradovic N, Stojanovic B. Tribological behaviour of ZA27/10SiC/1Gr hybrid composite. Journal of the Balkan Tribological Association. 2013;19:97-105. 